\title{
Diversidade genética entre acessos de espécies cultivadas de pimentas
}

\author{
Genetic diversity among accessions of cultivated peppers species
}

\author{
Eliane Rodrigues Monteiro ${ }^{I}$ Ethyenne Moraes Bastos ${ }^{\text {II }}$ Ângela Celis de Almeida Lopes ${ }^{\text {II }}$ \\ Regina Lucia Ferreira Gomes ${ }^{\text {III }}$ Jose Airton Rodrigues Nunes ${ }^{\text {IV }}$
}

\section{RESUMO}

O conhecimento da diversidade genética entre acessos em bancos de germoplasma é importante para fins de conservação de recursos genéticos e uso em programas de melhoramento genético. Neste estudo, objetivou-se avaliar a divergência genética entre 23 acessos de pimentas do gênero Capsicum, a partir de sete descritores quantitativos e 19 qualitativos multicategóricos, com auxílio de técnicas multivariadas. Pela análise de variância, evidenciaram-se diferenças significativas entre os acessos de pimentas para todos os descritores quantitativos. Os coeficientes de variação (CV) do experimento variaram de 8,97 (LF) a 30,91\% (NFA). O Método de agrupamento de otimização via Tocher detectou a formação de oito grupos, tanto para descritores quantitativos, quanto para os qualitativos multicategóricos. Pelo Método UPGMA, formaram-se três grupos baseando-se nos descritores quantitativos e quatro grupos com base nos qualitativos. Há diversidade genética inter e intraespecífica no Banco de Germoplasma de Capsicum spp. da Universidade Federal do Piauí, com evidências de que não existem duplicatas entre os acessos estudados.

Palavras-chave: Capsicum, descritores, técnicas multivariadas.

\section{ABSTRACT}

The knowledge of the genetic diversity among the accessions in germplasm banks it is important for the conservation of genetic resources and the use in breeding programs. This study aimed to evaluate the genetic divergence of 23 accessions of the genus Capsicum, and was based in seven quantitative and nineteen qualitative multicategorical descriptors and using multivariate techniques. The analyses of variance revealed significant difference $(P<0.05)$ among the accessions of peppers for all quantitative descriptors. The coefficient variation ranged from 8,97\% (LF) to 30,91\% (NFA). The Tocher optimization method detected eight clusters for quantitative descriptors and also in as well as qualitative multicategoric descriptors. The UPGMA method detected three clusters for quantitative descriptors and four clusters within qualitative multicategoricdescriptors. There is genetic diversity inter and intraspecific in germplasm bank of Capsicum coming from The Federal University of Piauí, and these results indicate that there are not duplicated accessions.

Key words: Capsicum, descriptors, multivariate techniques.

\section{INTRODUÇÃO}

A produção de pimenta no Brasil vem crescendo muito nos últimos anos, com cultivos em regiões de clima tropical e subtropical (RUFINO \& PENTEADO, 2006). Nesse sentido, há uma grande necessidade de novas cultivares que associem resistência às principais pragas e doenças a qualidades organolépticas e à produtividade, principalmente para atender ao setor agroindustrial (BENTO et al., 2007).

O Brasil é um importante centro de diversidade para o gênero Capsicum, por abrigar, tanto espécies domesticadas, quanto semidomesticadas e silvestres (CARVALHO et al., 2003). De acordo com MOSCONE et al. (2007), esse gênero compreende 31 espécies reconhecidas, algumas com variedades. A

'Departamento de Agronomia, Universidade Estadual de Maringá (UEM), 87030-070, Maringá, PR, Brasil. Email:eli.monteirobio@gmail.com. Autor para correspondência.

IIDepartamento de Biologia, Universidade Federal do Piauí (UFPI), Teresina, PI, Brasil.

'IIDepartamento de Fitotecnia, UFPI, Teresina, PI, Brasil.

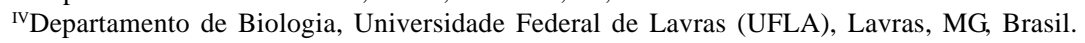


despeito das espécies domesticadas no mundo, PICKERSGILL (1997) e MOSCONE et al. (2007) afirmaram a existência de cinco, a saber: $\boldsymbol{C}$. annuum var. annuum, $C$. chinense, $C$. frutescens, $C$. baccatum variedades pendulum e umbilicatum, e C. pubescens). Essa grande diversidade existente tem fomentado os programas de melhoramento genético (REGO et al., 2003).

O estudo de diversidade genética é o processo pelo qual a variação entre indivíduos ou grupos de indivíduos ou populações é analisada por um método específico ou uma combinação de métodos. Os dados frequentemente envolvem medidas numéricas e, em muitos casos, combinações de diferentes tipos de variáveis. Métodos para classificar e ordenar a variabilidade genética possuem considerável significância. Técnicas analíticas multivariadas, as quais analisam simultaneamente múltiplas medidas de cada indivíduo, são amplamente utilizadas nesses estudos. Há dois tipos de métodos de agrupamento: os que se baseiam numa distância e os que se baseiam num modelo. Os primeiros se dividem em hierárquicos e não hierárquicos, sendo os mais frequentemente aplicados (MOHAMMADI \& PRASANNA, 2003; CROSSA \& FRANCO, 2004).

O emprego de procedimentos estatísticos multivariados é bastante vantajoso por considerar as correlações existentes entre os caracteres, permitindo distinguir as fontes de variabilidade genética e a importância de cada caráter avaliado em relação à divergência genética total (MOURA et al., 1999). Tais procedimentos são úteis na avaliação de acessos em bancos de germoplasma, no estabelecimento das relações entre as diversidades genética e geográfica, na prevenção da vulnerabilidade genética das culturas (NASCIMENTO FILHO et al, 2001), assim como na identificação de genitores adequados à obtenção de híbridos, com maior efeito heterótico (CRUZ \& CARNEIRO, 2003). Dessa forma, o conhecimento da diversidade genética entre acessos tem auxiliado no estabelecimento de corretas recomendações de cultivo e uso (CINTRA et al., 2005).

Com o propósito de avaliar acessos de pimentas do recém-criado Banco Ativo de Germoplasma de Capsicum da Universidade Federal do Piauí (BAGC/ UFPI), previamente identificados como pertecentes a quatro espécies cultivadas, objetivou-se avaliar a diversidade genética entre 23 acessos de pimentas mediante o uso de técnicas multivariadas, baseadas em descritores quantitativos e qualitativos multicategóricos.

\section{MATERIAL E MÉTODOS}

O experimento foi conduzido no Departamento de Fitotecnia, do Centro de Ciências Agrárias da UFPI, no Município de Teresina, Piauí, localizado a $05^{\circ} 05^{\prime}$ de latitude Sul e $42^{\circ} 05^{\prime}$ ' de longitude Oeste.

Foram utilizados 23 acessos de pimentas do Banco Ativo de Germoplasma de Capsicum da Universidade Federal do Piauí (BAGC/UFPI), obtidos por doações e coletas, previamente identificados e provenientes dos Estados do Piauí, Maranhão e São Paulo. Os acessos pertencem às espécies Capsicum chinense Jacq. (BAGC 3, 6, 8, 14, 15, 22, 31, 42, 47, 48, 52 e 55), Capsicum frutescens L. (BAGC 1, 2, 10, 37, 58 e 68), Capsicum baccatum L. (BAGC 32, 41 e 43) e Capsicum annuum L. (39 e 40).

O delineamento experimental foi em blocos ao acaso, com três repetições. Cada parcela foi constituída por sete plantas espaçadas de 1,0m x 0,8m. A adubação foi realizada em cova, utilizando-se NPK, na formulação comercial 4-14-8 (500g por metro de sulco) e esterco caprino (2,4kg cova $\left.{ }^{-1}\right)$, adotando-se o sistema de irrigação por gotejamento.

Para a caracterização e avaliação morfoagronômica dos acessos, foram utilizados 26 descritores, propostos pelo Biodiversity International (IPGRI, 1995), sendo sete quantitativos e 19 qualitativos multicategóricos. Os descritores quantitativos estudados foram: número de dias para a emergência (DE); número de flores por axila (NFA); número de sementes por fruto (NSF); comprimento do fruto, em cm (CF); largura do fruto, em cm (LF); peso do fruto, em gramas (PF); e espessura da polpa (EP), medida em milímetros, na região mais larga, com o auxílio de um paquímetro digital. Quanto aos descritores qualitativos, foram avaliados os seguintes: 1) relacionados à plântula - cor do hipocótilo, pubescência do hipocótilo, cor da folha e forma da folha cotiledonar; 2) relacionados à planta - cor do caule, posição da flor, cor da corola, cor da mancha da corola, cor das anteras, hábito de crescimento, cor da folha e forma da folha; e 3) relativos ao fruto - cor do fruto em estado intermediário; cor do fruto em estado maduro; forma do fruto; constrição anelar do cálice; margem do cálice; pescoço na base do fruto e tipo de epiderme.

Os dados de cada descritor quantitativo foram submetidos à análise de variância, e aqueles referentes aos descritores NSF, CF, LF e PF foram previamente transformados, sendo $\sqrt{x+1}$ para NSF e

para os demais. Posteriormente, foi realizado o teste de agrupamento das médias de Scott-Knott (SCOTT \& KNOTT, 1974), a 5\% de probabilidade de erro. 
Na análise de agrupamento, foram incluídos todos os descritores quantitativos. As características avaliadas apresentaram fraca colinearidade (número de condição $=45,84$ ), podendo ser utilizadas nas análises multivariadas. A divergência entre os acessos foi realizada pelos métodos de agrupamento de otimização via Tocher (RAO, 1952) e hieráquico via UPGMA (Unweighted Pair Group Method with Arithmetic Mean), com o emprego da distância de Mahalanobis como medida de dissimilaridade. A consistência do agrupamento pelo método hierárquico foi verificada por meio do coeficiente de correlação cofenética e, quanto mais próximo da unidade, melhor será a representação da matriz de similaridade na forma de dendrogramas.

A análise dos descritores qualitativos multicategóricos consistiu na obtenção da matriz de dissimilaridade com base nas concordâncias e/ou discordâncias observadas entre os acessos, utilizandose a moda, como medida descritiva de cada variável por acesso, desconsiderando as repetições e contabilizando todas as plantas representativas de cada acesso. Não ocorreu mais de uma moda por variável. Posteriormente, realizaram-se as análises pelos métodos de agrupamento de otimização via Tocher e hierárquico via UPGMA.

Todas as análises genético-estatísticas foram realizadas com auxílio do programa Genes (CRUZ, 2006).

\section{RESULTADOS E DISCUSSÃO}

Pela análise de variância, evidenciaram-se diferenças significativas entre os acessos de pimentas para todos os descritores quantitativos. Os coeficientes de variação (CV) do experimento variaram de 8,9\% (LF) a 30,91\% (NFA), sendo, portanto, satisfatórios, uma vez que foram detectadas diferenças significativas entre os acessos.

De acordo com os resultados obtidos no teste de Scott \& Knott, os acessos foram diferenciados em quatro grupos em relação ao descritor DE, sendo os acessos BAGC 14, 39, 40 e 43 os mais precoces (sete dias para emergência). Em relação ao NFA, os acessos possuidores de uma flor por axila ficaram num grupo, enquanto os que continham duas ou três flores ficaram em outro grupo. Quanto ao NSF, a média foi de 13 sementes por fruto, formando-se dois grupos com número de sementes abaixo da média e dois com número de sementes acima da média. Cinco grupos foram formados para CF e LF, ficando em um grupo o acesso BAGC 40 , com a maior média $(6,88 \mathrm{~cm})$, e no grupo de menor média $(<1,4 \mathrm{~cm})$ ficaram os acessos
BAGC 2, 6, 22, 48 e 55. O acesso BAGC 42 se diferenciou, por exibir a maior média de $\mathrm{LF}(3,55 \mathrm{~cm})$, já os acessos BAGC 1, 2, 10, 37, 40 e 58 apresentaram os frutos mais estreitos, com média de largura inferior a $0,8 \mathrm{~cm}$. Os acessos foram divididos em quatro grupos com base no PF, ficando em um mesmo grupo os acessos BAGC 42, 43 e 47, com as maiores médias (9,85g, 6,07g e 7,28g). Os acessos BAGC 1, 2, 10, 22, 37, 55 e 58 foram os mais leves, com média inferior a 0,8g. Com base na EP, os acessos foram diferenciados em três grupos. Os acessos 6, 8, 14, 15, 32, 41, 42,43, 47 e 48 formaram o grupo das polpas mais espessas (média $>2 \mathrm{~mm}$ ). Já os acessos BAGC 1, 2, 8, 10, 37, 40 e 68 apresentaram as polpas mais delgadas $(<1,3 \mathrm{~mm})$.

Pelo Método de agrupamento de otimização via Tocher, foram formados oito grupos, com base nos sete descritores quantitativos. O grupo I foi composto pelos acessos BAGC 6, 22, 55, 14, 41, 15, 31 e 39 pertencentes às espécies $\boldsymbol{C}$. chinense, $\boldsymbol{C}$. baccatum e C. annuum. Todas as amostras nesse grupo tiveram frutos pequenos, com médias para peso variando de 0,42g (BAGC 55) a 4,15g (BAGC 15), e comprimento entre $0,88 \mathrm{~cm}$ (BAGC 55) e 3,60cm (BAGC 15). O grupo II englobou os acessos BAGC 10, 37, 1, 3, 8, 68 e 52 pertencentes às espécies $\boldsymbol{C}$. frutescens e $\boldsymbol{C}$. chinense. Nesse grupo, as médias dos descritores PF, LF e CF variaram de 0,53g (BAGC 1) a 4,54g (BAGC 52), 0,66 cm (BAGC 1) a 1,83cm (BAGC 52) e 2,49cm (BAGC 1) a $5,26 \mathrm{~cm}$ (BAGC 52), respectivamente. O grupo III foi constituído por dois acessos de $\boldsymbol{C}$. frutescens (BAGC 2 e BAGC 58), que se destacaram por exibirem as menores médias para PF (0,14g e 0,28g), LF (0,44cm e $0,58 \mathrm{~cm})$ e CF (1,31 a 2,0cm). A variabilidade nesse grupo foi baixa, pois ele apresentou a menor distância intragrupo $(14,80)$. Segundo VASCONCELOS et al. (2007), o método de Tocher apresenta a distância média dentro dos grupos sempre menor que a distância média entre os grupos, portanto haverá mais homogeneidade entre os acessos de um mesmo grupo do que entre os acessos de diferentes grupos.

No grupo IV, foram alocados dois acessos de Capsicum chinense (BAGC 42 e BAGC 47). A média do número de sementes nesse grupo foi superior a 30 , e também foram registradas as maiores espessuras de polpa, as maiores larguras e os maiores pesos de frutos. Esse grupo foi o detentor da maior distância $(27,71)$, caracterizando variabilidade intrínseca. O acesso BAGC 43 ficou isolado no grupo $\mathrm{V}$, exibindo a maior média para PF (6,07g) dentre as espécies de $\boldsymbol{C}$. baccatum. O grupo VI foi constituído pelo acesso BAGC 48, conhecido como pimenta "bode vermelha". A presença de polpa espessa $(2,9 \mathrm{~mm})$ e a presença de maior média de número de dias para emergência (12 dias) 
contribuíram para a divergência deste em relação às demais da espécie $\boldsymbol{C}$. chinense. O grupo VII conteve somente o acesso BAGC 32 (C. baccatum), cujo comprimento foi o maior dentre os acessos dessa espécie $(4,06 \mathrm{~cm})$. Já o grupo VIII foi formado pelo acesso BAGC 40 (C. annuum), conhecido como pimenta “mexicana longa”, a qual exibiu a maior média para CF $(6,88 \mathrm{~cm})$.

A menor distância ocorreu entre o grupo V e o VI $(34,88)$. Nesses dois grupos, os valores para NSF e EP foram próximos. Já os grupos IV e o VIII foram os mais divergentes, pois exibiram a maior distância $(303,35)$. Os dois grupos divergiram em relação aos descritores CF, LF, PF e EP. De acordo com BENIN et al. (2002), os genótipos reunidos em grupos mais distantes dão um indicativo de serem dissimilares, podendo ser considerados como promissores em cruzamentos artificiais. Entretanto, além de dissimilares, é necessário que os genitores associem média elevada e variabilidade para os caracteres que estejam sendo melhorados.

De acordo com o dendrograma obtido pelo método hierárquico UPGMA (Figura 1), os acessos foram reunidos em três grupos considerando-se o corte a aproximadamente $53 \%$ da distância genética relativa, conforme o critério mencionado por CRUZ \& CARNEIRO (2003), no qual os pontos de alta mudança de nível são considerados delimitadores do número de genótipos para determinado grupo. O grupo I foi composto pelos acessos BAGC 6, 22, 55, 39, 14, 15, 47, $43,48,32$ e 41. No grupo II, ficaram os acessos 2, 58, 10, 37, 1, 3, 31, 8, 52, 68 e 40. Discordando do agrupamento de otimização via Tocher, o acesso 42 ficou isolado no grupo III, evidenciando a divergência deste em relação aos demais acessos. A largura desse acesso foi estatiscamente maior $(3,55 \mathrm{~cm})$. O valor do coeficiente de correlação cofenética foi de 0,72 .

O método hierárquico UPGMA e o método de agrupamento de otimização Tocher, baseados nos descritores quantitativos, foram concordantes ao formarem os grupos I e II.

O método de Tocher, baseado em 19 descritores qualitativos multicategóricos, possibilitou a formação de oito grupos distintos utilizando-se a matriz de dissimilaridade. O grupo I reuniu todos os acessos de $\boldsymbol{C}$. frutescens, denominados popularmente de "malaguetas", cujos frutos são muito picantes, embora haja exceção, como o acesso BAGC 58, denominado Malagueta doce. Esse grupo também se caracterizou por diferenças na cor dos frutos durante a maturação, passando de verde para laranja e depois para vermelho, quando maduros. A coloração dos frutos maduros é a principal característica considerada no desenvolvimento de cultivares para produção de páprica. Segundo CASALI \& STRINGUETA (1984), quanto maior o teor de pigmentos vermelhos, mais intensa é a coloração do pó.

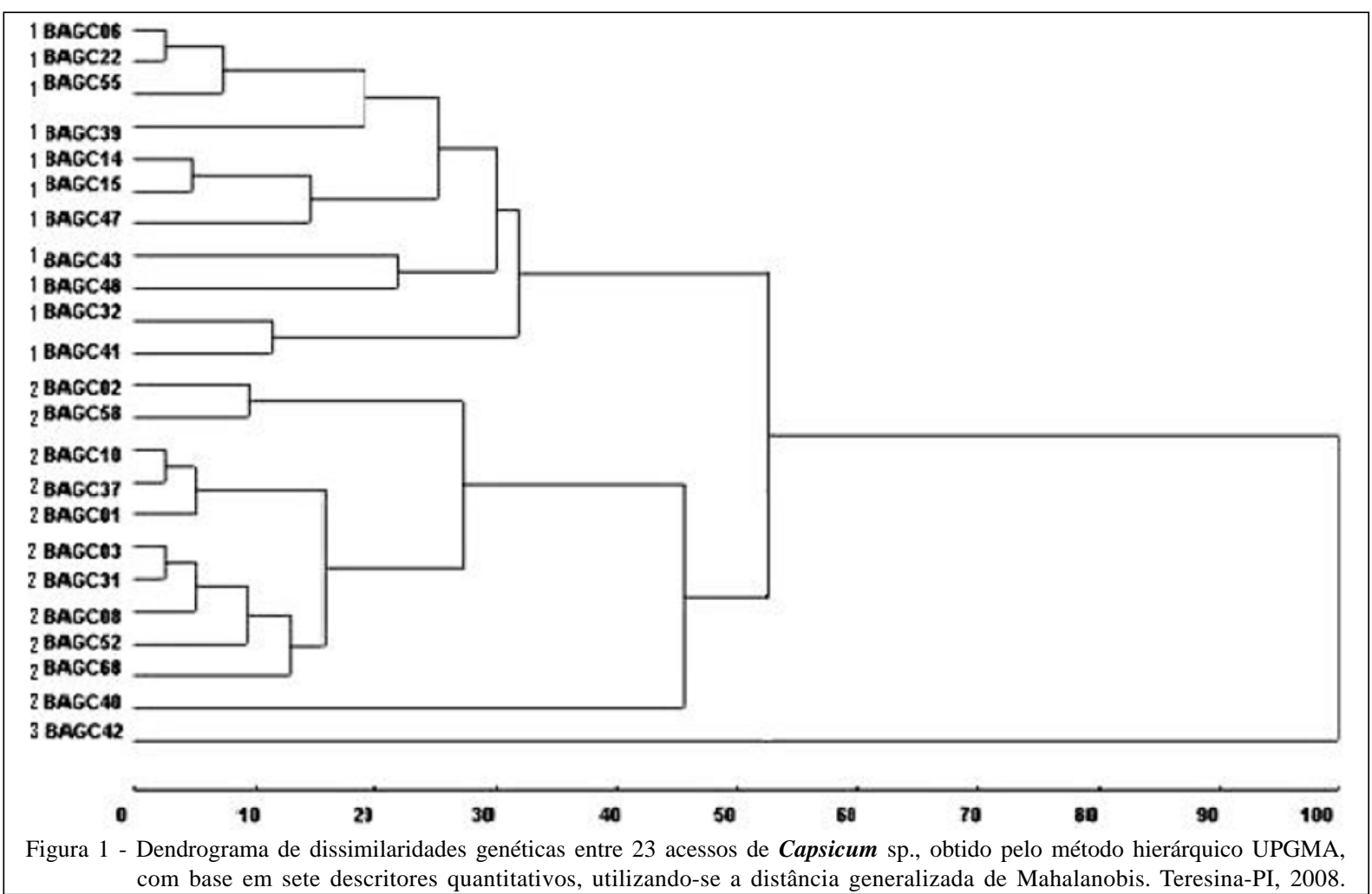

Ciência Rural, v.40, n.2, fev, 2010. 
Os grupos II, III, VI, VII e VIII foram compostos por acessos de $\boldsymbol{C}$. chinense. Esses grupos se diferenciaram principalmente em relação à posição da flor, cor e forma do fruto. O grupo IV foi constituído pelos acessos BAGC 39 e 40 (C. annuum.), conhecidos como mexicana roxa e mexicana longa, com 18 descritores em comum, e no grupo $\mathrm{V}$ ficaram os acessos de $\boldsymbol{C}$. baccatum (BAGC 41, 43 e 32), caracterizados por exibirem flores com anteras amarelas e corola branca com manchas amarelas.

O agrupamento pelo método hierárquico UPGMA formou quatro grupos, considerando-se o corte próximo a 73\% de distância genética (Figura 2). O grupo I reuniu todos os acessos de $\boldsymbol{C}$. frutescens (BAGC 02, 37, 58, 01, 10 e 68) e oito acessos de $\boldsymbol{C}$. chinense (BAGC 48, 03, 14, 15, 47, 52, 08 e 31). Nesse grupo predominaram os frutos de forma alongada. Essas duas espécies apresentam grande semelhança nas características morfológicas, sendo a constrição anelar do cálice o descritor que separa as duas espécies (PICKERSGILL, 1971). O grupo II foi formado pelos acessos BAGC 06, 22, 55 e 42 (C. chinense Jacq.), todos com frutos de forma arredondada. O grupo III foi constituído pelos acessos BAGC 41, 43 e 32 (C. baccatum L.), tendo como característica exclusiva a presença de mancha na corola. No grupo IV, ficaram os acessos BAGC 39 e BAGC 40 (C. annuum L.). O valor do coeficiente de correlação cofenética foi de 0,86.

Comparando-se os agrupamentos obtidos pelo método hierárquico UPGMA e pelo método de agrupamento de otimização via Tocher, com base nos descritores qualitativos, observou-se uma concordância, destacando-se a coincidência dos acessos constantes nas mesmas formações de grupos, no caso aqueles presentes nos grupos $\mathrm{V}$ e IV assinalados pelo método de Tocher.

Os descritores qualitativos multicategóricos permitiram uma melhor diferenciação interespecífica em relação aos descritores quantitativos provavelmente em função do tipo de herança gênica, pois tais descritores são controlados por poucos genes e, portanto, menos afetados pelo ambiente.

A maioria dos acessos analisados pertencem à espécie $\boldsymbol{C}$. chinense, sendo essa a mais divergente em todos os agrupamentos, apresentando as maiores distâncias intragrupo e formando o maior número de grupos. Os acessos BAGC 22 e BAGC 55, BAGC 14 e BAGC 15 foram divergentes apesar da semelhança fenotípica. Assim, de acordo com o estudo realizado, há evidências de que não existem duplicatas.

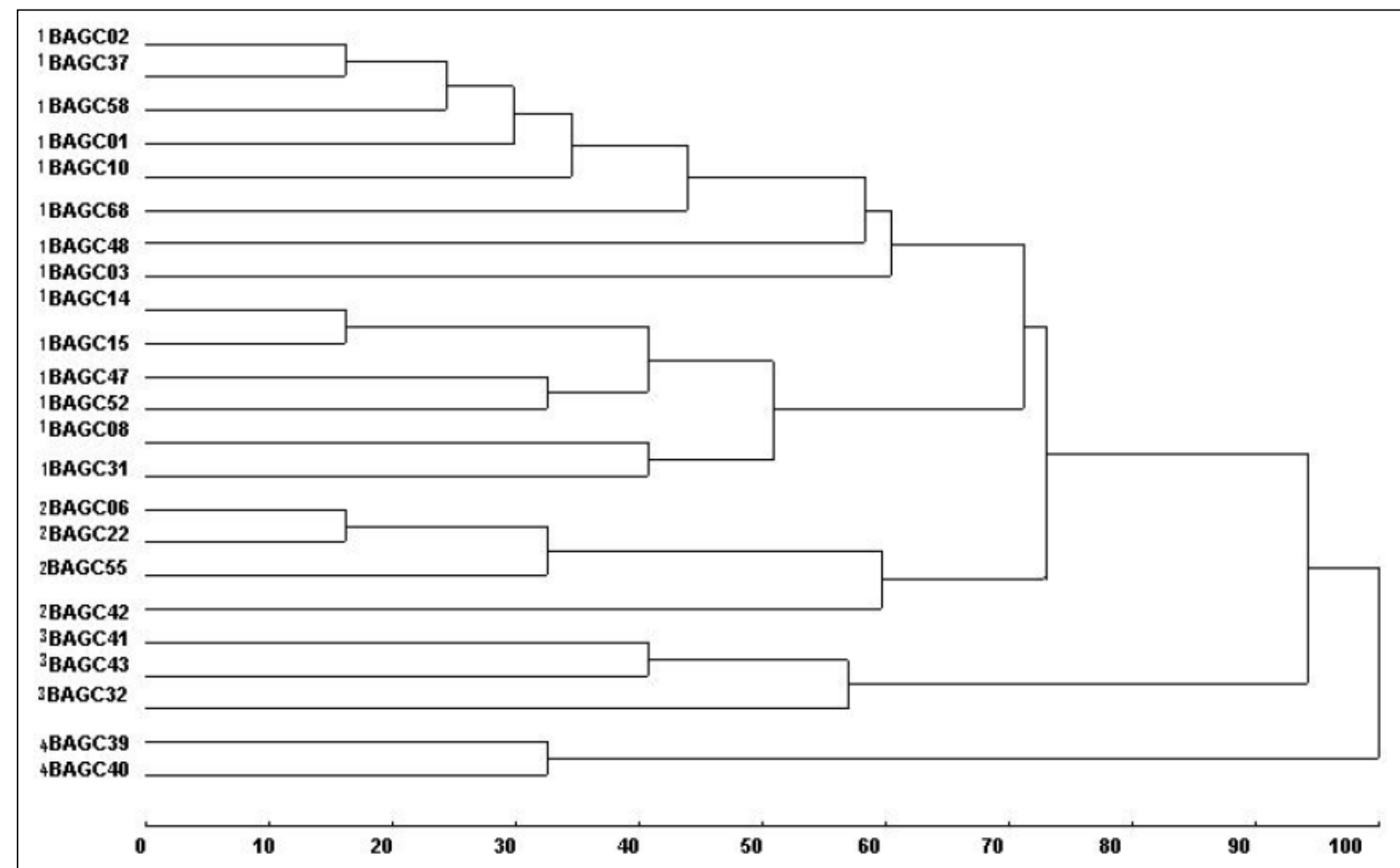

Figura 2 - Dendrograma de dissimilaridades genéticas entre 23 acessos de Capsicum spp., obtido pelo método hierárquico UPGMA, com base em 19 descritores qualitativos mul-ticategóricos, utilizando-se a matriz de dissimilaridade. Teresina, PI, 2008.

Ciência Rural, v.40, n.2, fev, 2010. 
Conforme evidenciou a análise de diversidade, os 23 acessos do Banco Ativo de Germoplasma de Capsicum da UFPI devem ser mantidos. A existência de variabilidade permite que esses acessos sejam utilizados em programas de melhoramento, cujos frutos poderão ser direcionados ao mercado in natura ou a indústrias de molhos ou conservas. Outra possibilidade é o uso das pimenteiras como plantas ornamentais.

\section{CONCLUSÕES}

Há diversidade genética inter e intraespecífica no Banco Ativo de Germoplasma de Capsicum spp. da Universidade Federal do Piauí, com evidências de que não existem duplicatas entre os acessos estudados.

\section{AGRADECIMENTO}

À Universidade Federal do Piauí, pelo espaço concedido para a realização do experimento.

\section{REFERÊNCIAS}

BENIN, G. et al. Identificação da dissimilaridade genética entre genótipos de feijoeiro comum (Phaseolus vulgaris l.) do grupo preto. Revista Brasileira de Agrociência, v.8, p.179-184, 2002. Disponível em: <http://www.ufpel.tche.br/faem/ agrociencia/v8n3/artigo01.pdf>. Acesso em: 16 nov. 2007.

BENTO, C.S. et al. Descritores qualitativos e multicategóricos na estimativa da variabilidade fenotípica entre acessos de pimentas. Scientia Agraria, v.8, p.149-156, 2007. Disponível em: <http://ojs.c3sl.ufpr.br/ojs2/index.php/agraria/article/ viewFile/8379/666>. Acesso em: 28 jan. 2008

CARVALHO, S.I.C. et al. Catálogo de germoplasma de pimentas e pimentões (Capsicum spp.) da Embrapa Hortaliças. Brasília, DF: Embrapa Hortaliças, 2003. 49p.

CASALI, V.W.D.; STRINGHETA, P.C. Melhoramento de pimentão e pimenta para fins industriais. Informe Agropecuário, v.10, p.23-24, 1984.

CINTRA, M.M.D.F. et al. Genetic divergence among Curcuma longa L. accessions. Crop Breeding and Applied Biotechnology, v.5, p.410-417, 2005. Disponível em: <http:/ /www.sbmp.org.br/cbab/siscbab/uploads/bd6b8337-51dd4fe7.pdf>. Acesso em: 01 dez. 2007.

CROSSA, J.; FRANCO, J. Statistical methods for classifying genotypes. Euphytica, v.137, p.19-37, 2004. Disponível em: <http:/ /www.springerlink.com/content/gj02373lk01n8382>. Acesso em: 11 maio 2009. doi: 10.1023/B:EUPH.0000040500.86428.e8.
CRUZ, C.D.; CARNEIRO, P.C.S. Modelos biométricos aplicados ao melhoramento genético. Viçosa: UFV, 2003. 585p.

CRUZ, C.D. Programa genes: análise multivariada e simulação. Viçosa: UFV, 2006. 175p.

IPGRI. Descriptores para Capsicum (Capsicum spp). Roma, $199551 p$.

MOHAMMADI, S.A; PRASANNA, B.M. Analysis of genetic diversity in crop plants - salient statistical tools and considerations. Crop Science, v.43, p.1235-1248, 2003. Disponível em: <http://crop.scijournals.org/cgi/reprint/43/4/ 1235>. Acesso em: 11 maio 2009.

MOSCONE et al. The evolution of Chili Peppers (Capsicum Solanaceae): a cytogenetic perspective. Acta Hort, v.745, p.137170, 2007. Disponível em: <http://www.actahort.org/books/745/ 745_5.htm>. Acesso em: 19 maio 2009.

MOURA, W.M. et al. Divergência genética em linhagens de pimentão em relação à eficiência nutricional de fósforo. Pesquisa Agropecuária Brasileira, v.34, p.217-224, 1999. Disponível em: <http://www.scielo.br/pdf/pab/v34n2/8731.pdf>. Acesso em: 01 dez. 2007

NASCIMENTO FILHO, F. J. et al. Divergência genética entre clones de guaranazeiro. Pesquisa Agropecuária Brasileira, v.36, p.501-506, 2001. Disponível em: <http://www.scielo.br/ pdf/pab/v36n3/4793.pdf>. Acesso em: 16 nov. 2007.

PICKERSGILL,B. Relationships between weedy and cultivated forms in some species of chili peppers (genus Capsicum). International Journal of Organic Evolution, v.25, p.683691, 1971. Disponível em:<http://www.jistor.org/pss/2406949>. Acesso em: 14 jan. 2008, doi:10.2307/2406949.

PICKERSGILL,B. Genetic resources and breeding of Capsicum spp. Euphytica, v.96, p.129-133, 1997. Disponível em:<http:/ /www.springerlink.com/content/w1h5437x32531771>. Acesso em: 07 mar. 2007 doi: 10.1023/A:1002913228101.

RAO, R.C. Advanced statistical methods in biometric research. New York: John Wiley, 1952. 390p.

REGO, E.R. et al. Genetic diversity analysis of peppers: a comparison of discarding variable methods. Crop Breeding and Applied Biotechnology, v.3, p.19-26, 2003. Disponível em: <http://www.sbmp.org.br/cbab/siscbab/uploads/c8128f429aca-6335.pdf $>$. Acesso em:14 fev. 2008.

RUFINO, J.L.S.; PENTEADO, D.C.S. Importância econômica, perspectivas e potencialidades do mercado para pimenta. Informe Agropecuário, v.27, p.7-15, 2006.

SCOTT, A.J.; KNOTT, M. A cluster analysis method for grouping means in the analysis of variance. Biometrics, v.30, p.507512, 1974

VASCONCELOS, E.S. et al. Método alternativo para análise de agrupamento. Pesquisa Agropecuária Brasileira, v.42, p.1421-1428, 2007. Disponível em: http://www.scielo.br/pdf/ pab/v42n10/a08v4210.pdf. Acesso em: 28 jan. 2008. 